\author{
SERIES 'LUNG HYPERINFLATION IN RESPIRATORY INTENSIVE CARE' \\ Edited by V. Brusasco and J.W. Fitting \\ Number 2 in this Series
}

\title{
Lung volume reduction surgery for emphysema
}

\author{
E.W. Russi*, U. Stammberger ${ }^{+}$, W. Weder ${ }^{+}$
}

\begin{abstract}
Lung volume reduction surgery for emphysema. E.W. Russi, U. Stammberger, W. Weder. CERS Journals Ltd 1997.

ABSTRACT: Lung volume reduction surgery (LVRS) is performed to alleviate dyspnoea of selected patients with severe pulmonary emphysema and to improve their pulmonary function, performance in daily activity and quality of life. By resection of destroyed lung areas the achievable improvements in function may consist of: 1) a reduction in hyperinflation resulting in amelioration of diaphragm and chest wall mechanics; 2) an increase of elastic recoil pressure, thereby augmenting expiratory flow rates; and 3) possibly an improvement in gas exchange.

Meticulous selection of suitable patients, refinements in operative techniques, anaesthesiological and postoperative management has lowered perioperative mortality to less than $5 \%$ in groups who are experienced with this type of procedure.

The best functional results are achieved by bilateral resection, which can either be performed by median sternotomy or by video-assisted thoracoscopy (VAT). The average increase in forced expiratory volume in one second (FEV1), obtained by bilateral resection in patients already receiving optimal medical therapy ranges $32-93 \%$, and the reduction in hyperinflation, assessed by a decrease in total lung capacity ranges $15-20 \%$. These favourable improvements have been reported to last in most of the patients for at least one year.

Eur Respir J., 1997; 10: 208-218.
\end{abstract}

*Dept of Internal Medicine, Division of Pneumology and +Dept of Surgery, University Hospital, CH-8091 Zurich, Switzerland.

Correspondence: E.W. Russi

Pulmonary Division

Dept of Internal Medicine

University Hospital

Raemistr. 100

CH-8091 Zurich

Switzerland

Keywords: Hyperinflation lung volume reduction surgery pulmonary emphysema

Received: August 11996

Accepted after revision November 151996

Supported by grants from the Swiss National Science Foundation and the Zurich Lung League
Chronic obstructive pulmonary disease (COPD) is a major cause of morbidity and mortality. In the European Union, COPD, asthma and pneumonia are the third most common cause of death. In North America, COPD is the fourth most common cause of death, and mortality rates and prevalence are increasing [1].

COPD is characterized by reduced maximum expiratory flow, which does not markedly change over several months [2]. The airflow limitation is due to varying combinations of airways disease and emphysema. Pulmonary emphysema is defined anatomically by permanent destructive enlargement of airspaces distal to the terminal bronchioles without obvious fibrosis [3]. Patients with the most severe type of COPD usually present with a considerable degree of emphysema, which is suspected when total lung capacity (TLC) is elevated, the ratio of residual volume (RV) to total lung capacity (RV/TLC) is increased and the single-breath carbon monoxide transfer factor $(T \mathrm{~L}, \mathrm{CO})$ is reduced. An increase in static pulmonary compliance, a decrease in lung recoil pressure at a given lung volume and a change in the shape of the static pressure volume curve are also characteristic of pulmonary emphysema. However, such measurements are rarely performed in clinical practice. The presence of emphysema of moderate to severe degree can be appraised on a plain posteroanterior and lateral chest radiograph and is reliably assessed by high resolution computed tomography (HRCT).

Major pathophysiological consequences of emphysema can be attributed to a loss of elastic recoil, and consist of static and dynamic hyperinflation as well as a preferential obstruction of expiratory airflow due to a loss of traction on the airways, which leads to intrinsic positive end-expiratory pressure (PEEP) and increased work of breathing [4]. The main symptom of patients with very advanced emphysema is shortness of breath during minimal physical activity. This is mainly a consequence of impaired pulmonary mechanics.

COPD is often diagnosed late in its course, because patients may lack symptoms, even at a low forced expiratory volume in one second $\left(\mathrm{FEV}_{1}\right)$. The only intervention documented to reduce the rapid decline in FEV1 is cessation of smoking [5] and the sole treatment proved to prolong life is the long-term use of continuous home oxygen [6,7]. In patients with very advanced disease, other therapeutic interventions such as inhalation of betaadrenergics and anticholinergics may ameliorate symptoms and therefore improve quality of life, but have only minor effects on pulmonary function tests. On the other hand pulmonary rehabilitation does not alter pulmonary function but can improve exercise performance [8, 9]. Until recently lung transplantation remained the only effective method to improve symptoms and performance in patients with advanced nonbullous emphysema. Lung volume reduction surgery (LVRS) has become a novel palliative procedure for a subgroup of patients with advanced emphysema. Several groups worldwide are currently investigating the selection criteria, the optimal surgical treatment, physiological changes and long term effects of this intervention. 


\section{History of emphysema surgery}

Numerous procedures were developed for the relief of dyspnoea or other symptoms of COPD. Such operations included costochondrectomy, thoracoplasty and phrenicectomy, stabilization of the membranous trachea, glomectomy, lung denervation etc. [10]. Most of these interventions attempted to treat the wrong physiological or anatomical deficit with the consequence that mid- or long-term results were unpredictable or even disastrous.

REICH [11], in Vienna in 1924, was the first to study the effect of pneumoperitoneum on the ventilation of patients with emphysema. In 1950 GAENSLER and coworkers $[12,13]$ investigated the functional effects of pneumoperitoneum in a more systematic way. Their first three patients had received pneumoperitoneum for the treatment of active tuberculosis and were observed to be less short of breath when pneumoperitoneum was induced, and became severely dyspnoeic when it was omitted. These patients had marked pulmonary emphysema due to shrinking fibrosis secondary to tuberculosis. Gaensler's group [13] subsequently investigated the effect of pneumoperitoneum in patients suffering from emphysema not associated with tuberculosis. The most impressive change observed was an increased tussive force and more than half of the patients reported an improvement of dyspnoea. Mean vital capacity increased from 2000 to $2350 \mathrm{~mL}$, mean residual volume, measured by the nitrogen dilution technique, decreased from 2.6 to $2.0 \mathrm{~L}$, and the maximum breathing capacity improved from a mean of $29 \mathrm{~L} \cdot \mathrm{min}^{-1}$ before to $37 \mathrm{~L} \cdot \mathrm{min}^{-1}$ after treatment. We estimate that the FEV1, which was not measured at that time, had increased from approximately $800 \mathrm{~mL}$ to about $1 \mathrm{~L}$. Diaphragmatic excursion was assessed by fluoroscopy and was seen to improve in most of the patients examined. The authors considered the beneficial effect of pneumoperitoneum to be mainly due to the restoration of the physiological dome of the diaphragm, and hence a more efficient contraction of this muscle.

As early as 1950 in Baltimore, BRANTIGAN and coworkers [14], started to operate on patients who were severely impaired due to bilateral diffuse and bullous emphysema. They reasoned that in patients with distended lungs due to severe emphysema, the normal outward circumferential pull on the bronchioles had been lost, causing them to collapse during expiration. It was suggested that reducing overall lung volume would restore the outward elastic traction on the small airways and reduce expiratory airway obstruction. Multiple lung resections and plications were performed through a standard thoracotomy. Of 89 evaluated patients 56 underwent the operation, and 14 were operated on both sides. Results from the first 33 patients were published in 1957 [14] and from a further 56 patients in $1961[15,16]$. Significant clinical improvement was claimed by $75 \%$ of the patients, and this improvement persisted in some for more than five years [16]. However, as the rate of early mortality was $16 \%$, and little objective data were reported to substantiate claims of subjective improvement, Brantigan's procedure never gained widespread acceptance.

In 1993 COOPER and co-workers [17] resumed Brantigan's approach and performed bilateral lung volume reduction in patients with grossly hyperinflated lungs suffering from severe diffuse pulmonary emphysema. They used median sternotomy as a surgical approach. Based on observations made in patients undergoing lung transplantation for severe pulmonary emphysema and previous experience in bilateral resection of emphysematous bullae by median sternotomy [18], COOPER and co-workers [17] supposed, that in certain patients Brantigan's principles might apply. They assumed, that reduction of the lung volumes would allow the restoration of a normal chest cage and diaphragmatic position, enabling the patient to take deeper breaths (fig. 1).

Another important observation related to their experience during anaesthesiological management of patients undergoing lung transplantation for emphysema [17, 19]. Unexpectedly, intraoperative gas exchange during contralateral one-lung ventilation was always sufficient and cardiopulmonary bypass was rarely necessary.

\section{The modern concept of surgery for emphysema}

A clear distinction needs to be made between surgery for giant bullae and surgery for diffuse emphysema. Surgery has been used successfully for more than four decades to improve lung function in patients with giant bullous emphysema. Patients with bullae larger than one third of a hemithorax and an FEV1 of less than $50 \%$ of predicted seemed to benefit most [20]. The improvements in pulmonary function were assumed to result from decompression of adjacent lung tissue by the removal of large, space occupying bullae. The different aspects of surgery for giant bullous emphysema were recently discussed by SNIDER [21], who reviewed 22 case series including 476 patients.

Modern surgery for diffuse emphysema is based on the concept of BRANTIGAN and co-workers $[14,15]$ which was revived by COOPER and co-workers [17]. The goals of LVRS are: an improvement of the lungs elastic recoil to create enhanced radial traction on the airways, thus lowering airway resistance and increasing driving force for maximal expiratory flow; and a reduction in pulmonary hyperinflation enabling the diaphragm to regain a more physiological configuration for generating inspiratory force and working in a more efficient manner (fig. 1).

\section{Patient evaluation and selection}

Patient evaluation has as its goal the selection of those patients who will subjectively and objectively benefit most from LVRS at a minimal risk for perioperative mortality and postoperative morbidity. Our selection criteria (table 1) were initially based on those of COOPER et al. [17]. They have been modified according to our personal experience and continue to evolve based on ongoing analysis of patients outcome.

Suitable patients are identified according to the following functional, personal and anatomical aspects: 1) the obstruction to airflow is severe and mainly due to emphysema; 2) the pulmonary hyperinflation is severe; 3 ) the patients daily performance is severely impaired 
a)

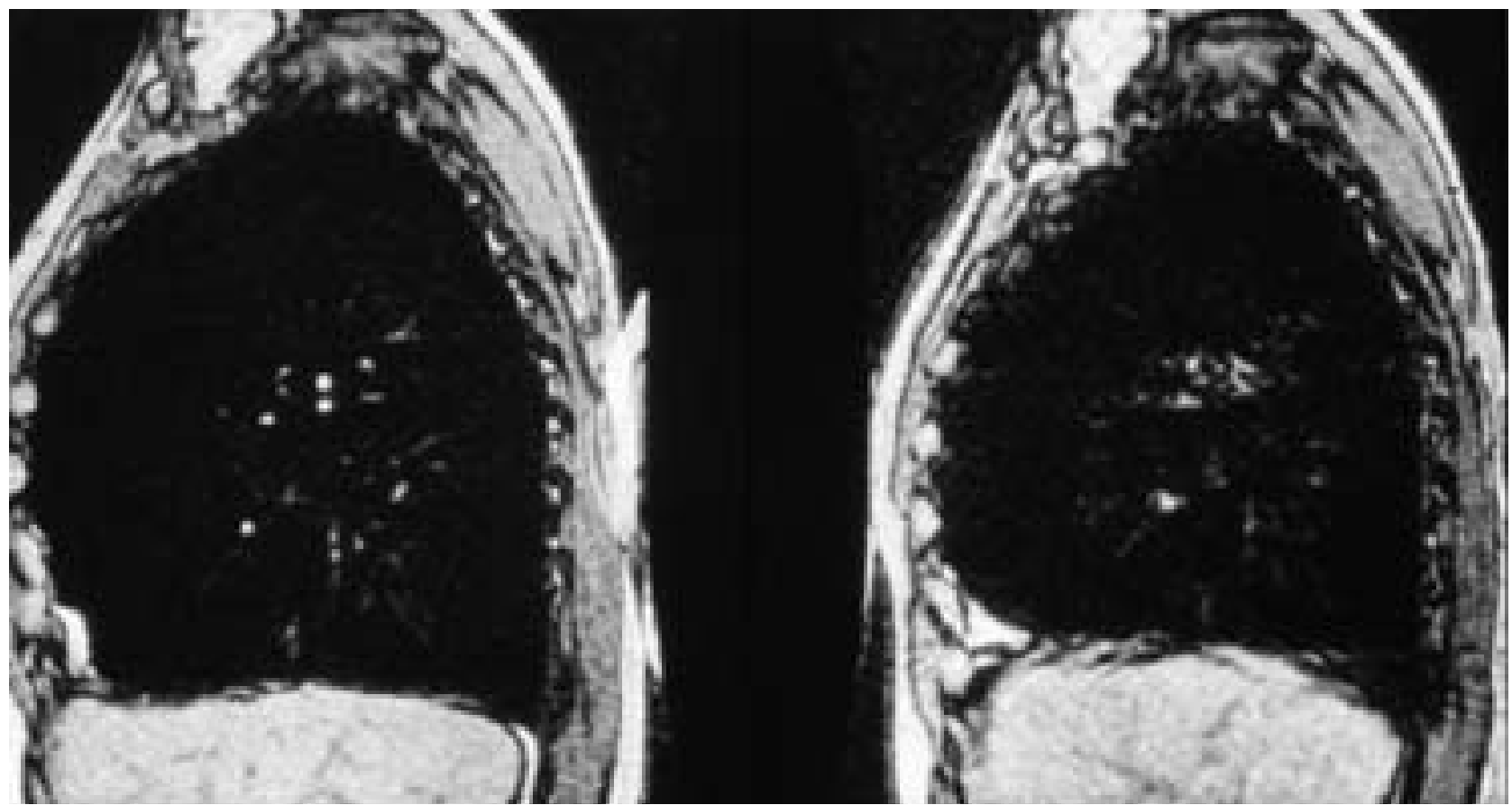

b)

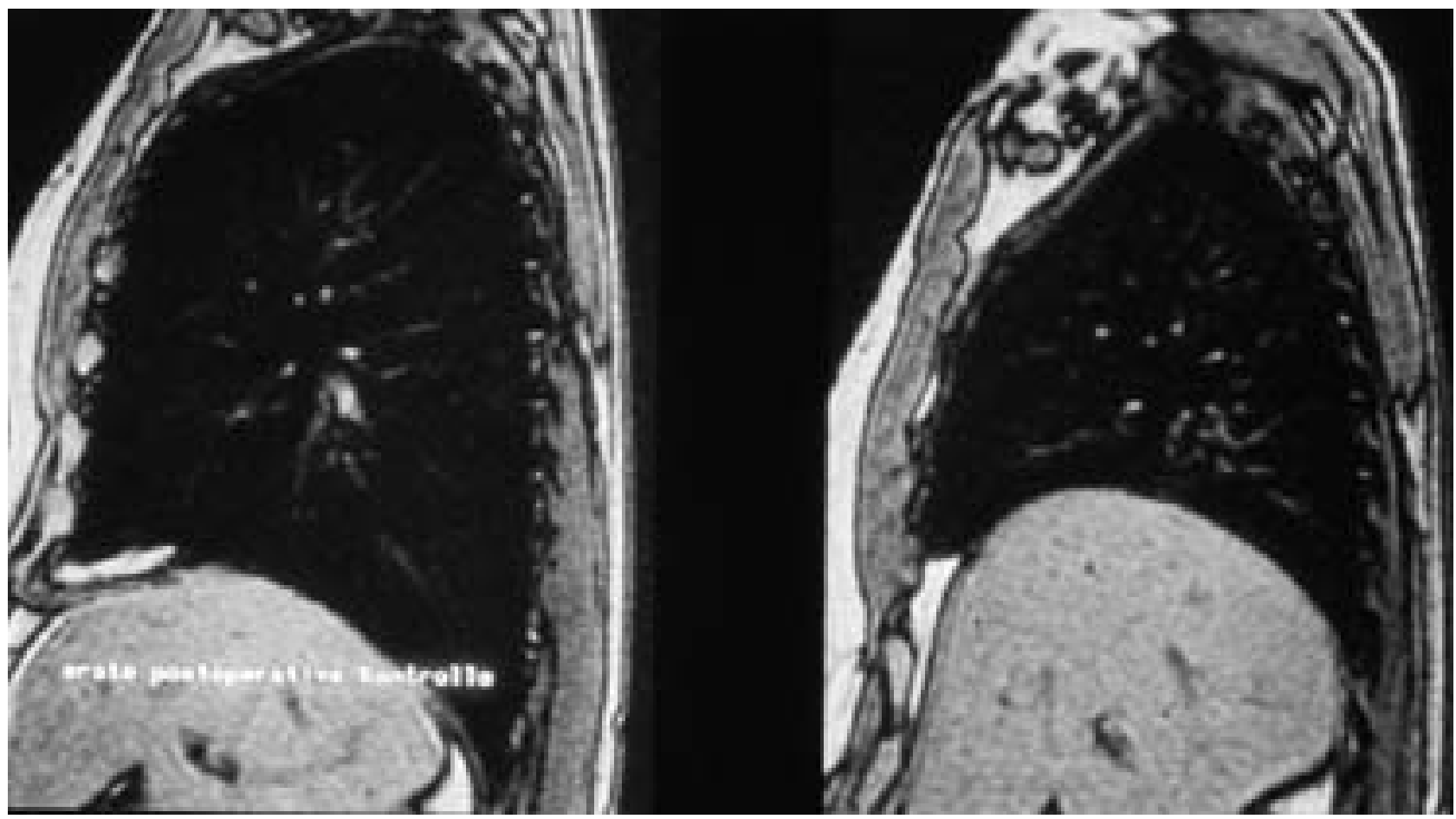

Fig. 1. - Midsagittal nuclear magnetic resonance images before: (a) and after (b) LVRS from the same patient. The chest is overdistended and the flattened diaphragm shows minimal excursion during inspiration (left) and expiration (right). After surgery the diaphragm is curved and the excursion is improved.

as a consequence of this functional impairment and results in a reduced quality of life; 4) no further improvement can be achieved by pharmacotherapy (including corticosteroids) and comprehensive pulmonary rehabilitation; 5) the patient is highly motivated to undergo a surgical procedure with an increased risk and is in a stable psychic condition; and 6) it is believed that the ideal candidate has an emphysema with marked heterogeneity predominantly localized in both upper lobes (fig. 2) $[22,23]$. In addition patients with a less heterogeneous type of emphysema with less distinct "target areas" for resection (fig. 3) may profit from LVRS.

Patients should have participated in a comprehensive pulmonary rehabilitation program consisting of exercise 
Table 1. - Patient selection for LVRS in Zurich

\section{Inclusion criteria}

Dyspnoea at rest or at minimal physical activity resulting in severe limitation of daily activity associated with an impaired quality of life.

High motivation and acceptance of an increased perioperative mortality (approximately 5\%) and/or morbidity (long lasting hospitalization due to prolonged air leaks) and willingness to undergo follow-up examinations after informed consent.

Severe obstructive ventilatory defect (FEV $1<35 \%$ pred).

No significant improvement of the bronchial obstruction (changes of FEV $1<15 \%$ ) by the usual antiobstructive pharmacotherapy including a prolonged trial with systemic corticosteroids (i.e. negative steroid trial).

Functional aspects of lung emphysema, i.e. irreversible hyperinflation with RV $>200 \%$ pred TLC $>130 \%$ pred and an impaired $T_{\mathrm{L}, \mathrm{CO}}$

Radiological evidence of pulmonary emphysema including signs of hyperinflation with flat diaphragms.

Emphysema confirmed by HRCT.

Candidate for lung transplantation but $>60$ yrs of age, or $<60$ yrs of age but strong preference for this type of procedure.

Exclusion criteria

Patient continues to smoke.

Age 75 yrs.

"Vanishing lung" on CT.

$T$ L,CO $<20 \%$ pred.

Hypercapnia with $\mathrm{Pa}_{\mathrm{a}, \mathrm{CO}_{2}}>7.3 \mathrm{kPa}(55 \mathrm{mmHg})$.

Coronary artery disease ( $>50 \%$ diameter reduction) of more than one coronary artery that can not be improved by coronary angioplasty.

Left ventricular impairment of ischaemic or other aetiologies.

Pulmonary hypertension with a mean pulmonary arterial pressure $>4.7 \mathrm{kPa}(35 \mathrm{mmHg})$ at rest.

Acute bronchopulmonary infection, bronchiectases on HRCT.

Pulmonary cachexia (BMI $<18 \mathrm{~kg} \cdot \mathrm{m}^{-2}$ ).

Neoplastic disease with a life expectancy of less than 2 yrs.

Addiction to alcohol or drugs, psychiatric disturbance (e.g. panic disorder).

Relevant renal (creatinine $>150 \mu \mathrm{g} \cdot \mathrm{mL}^{-1}$ ), gastroenterological (history of GI-bleeding in the previous year, abnormal liver function tests, active inflammatory bowel disease) or neurological disease (history of cerebrovascular events).

Oral corticosteroids at a dose of $>15 \mathrm{mg}$ of prednisolone equivalent.

LVRS: lung volume reduction surgery; FEV1: forced expiratory volume in one second; $\%$ pred: percentage of predicted; TLC: total lung capacity; $T \mathrm{~L}, \mathrm{CO}$ : transfer capacity of the lung for carbon monoxide; HRCT:high resolution computed tomography; CT: computed tomography; BMI: body mass index; GI: gastrointestinal.

and coping skills training as well as nutrition therapy. They are only accepted for surgery, if the changes achieved by these measures remain unsatisfactory.

Most exclusion, and some of the inclusion criteria (table 1) are rather arbitrary, since they have not been prospectively validated with regard to their predictive accuracy. They may serve as guidelines to avoid operations on patients with too much mechanical impairment (FEV $1<15 \%$ of predicted, marked hypercapnia) or insufficient lung tissue left ("vanishing lung" on computed tomography (CT) and/or TL,CO $<20 \%$ of predicted) for adequate gas exchange. Furthermore, patients with coexisting major medical problems, particularly coronary artery heart disease, that would considerably increase the operative risk should be excluded. The selection of a patient who might profit from this type of surgery at a justifiable perioperative risk is a synoptic process. Candidates should not be excluded from surgery if some of the inclusion criteria are not met, or on the basis of a single contraindication.

Our initial evaluation consists of clinical, functional and radiological examinations (table 2). From May 1994 to April 1996 we have evaluated 88 patients. Of these, 36 were operated upon and four are waiting for surgery. Forty eight patients, (nine females and 39 males) with a mean age of 64 yrs were excluded from further evaluation for the following reasons: 18 did not accept an increased risk of perioperative mortality; in 10 patients the functional impairment was not severe enough; three patients were not sufficiently hyperinflated; eight patients had coronary artery heart disease; and eight for various other medical reasons. One patient was considered to be a primary candidate for lung transplantation. This high acceptance rate for surgery is in accordance with that of YUSEN et al. [24], who accepted 189 of 440 patients invited for an on-site evaluation, and is a consequence of an excellent preselection by the referring pulmonary physicians who were thoroughly informed about our actual selection criteria.

We currently perform right heart catheterization in all of our candidates, but only for study purposes. Furthermore, men older than 50 and women older than 55 yrs undergo left heart catheterization as well as coronary angiography. Since all of our patients were former smokers and most of them of advanced age, they belong to a high risk group for coronary artery disease (CAD). Due to extreme ventilatory impairment they are unable to perform a meaningful cardiac exercise test. Relevant CAD, which had an impact on the individual treatment strategy (LVRS denied or preoperative angioplasty), was found in $15 \%$ of our asymptomatic patients (unpublished results). We believe, that exclusion of significant CAD is mandatory before surgery. However, to reduce the number of normal coronary angiograms, dipyridamolethallium scintigraphy, a method known to be sensitive for the detection of CAD, can be performed to screen patients.

Before a patient is definitively scheduled for surgery the following potential problems should be reconsidered and treated preoperatively: bronchopulmonary infection is treated according to sputum cultures (e.g. Pseudomonas aeruginosa) by antibiotics; patients who were on longterm corticosteroids should not be withdrawn from their maintenance dose, which will need to be increased perioperatively; and those patients who are extremely impaired in their performance (e.g. confined to a wheelchair) and who are in an unfavourable condition due to muscle weakness or poor nutritional status should once more undergo pulmonary rehabilitation.

Furthermore, in the preoperative period all patients should be instructed by the respiratory therapist in the breathing exercises planned for the early postoperative phase.

\section{Operative techniques, anaesthesia and postopera- tive management}

LVRS can be performed through a median sternotomy, a thoracotomy or by video-assisted thoracoscopy (VAT). 
a)

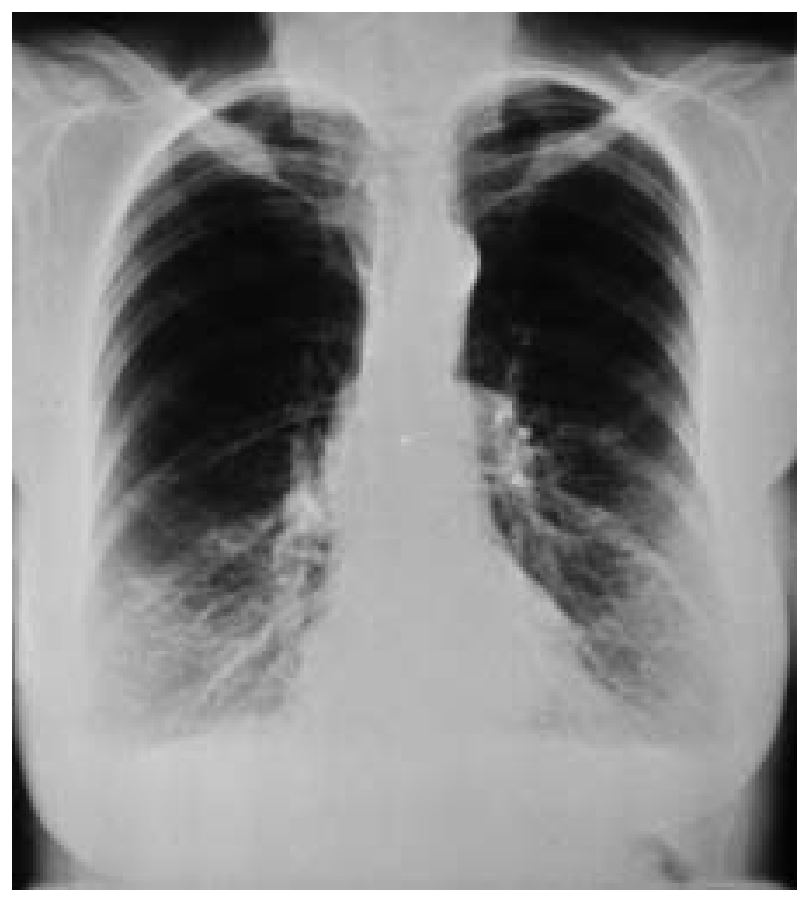

b)

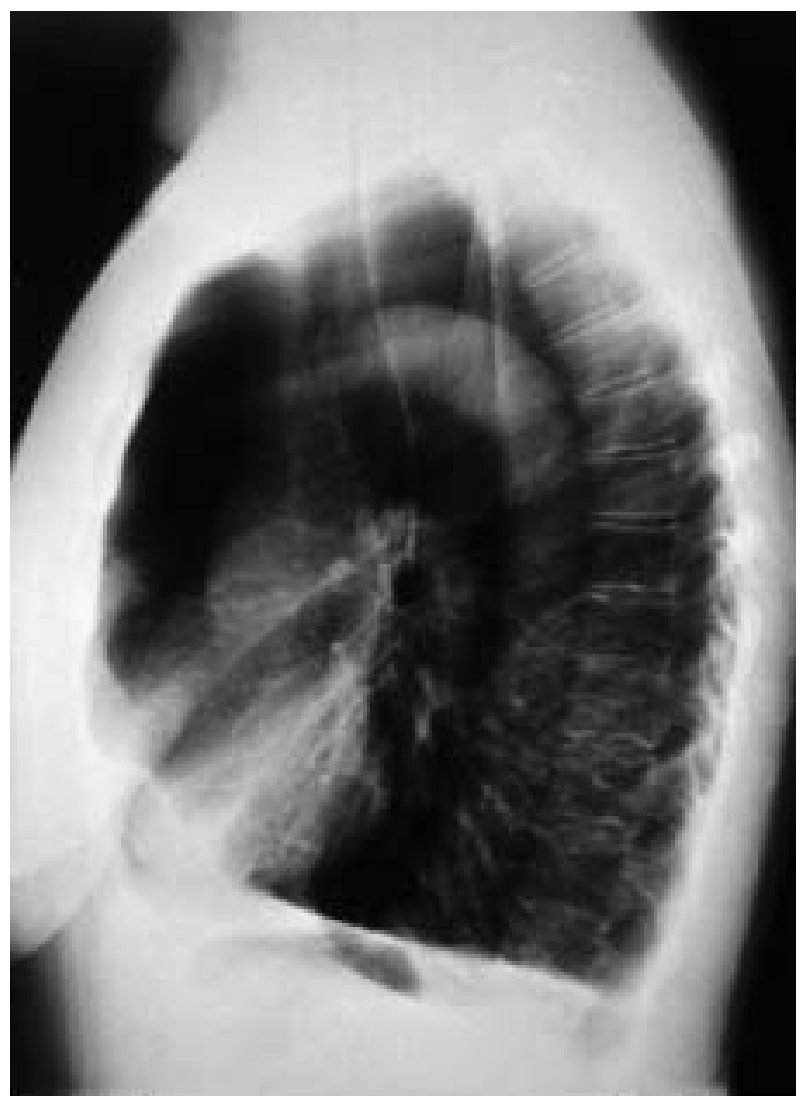

c)

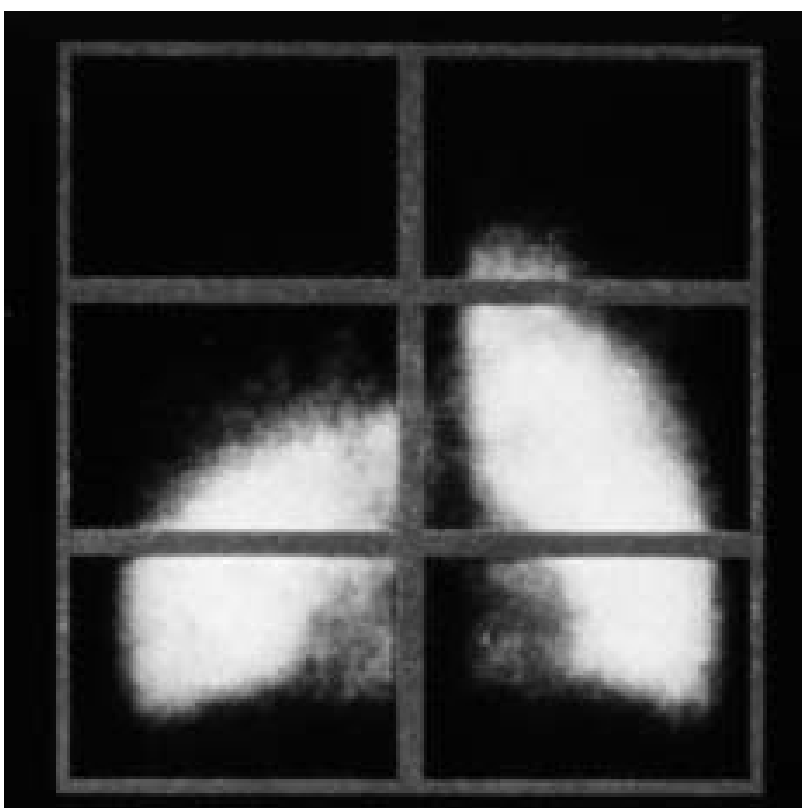

d)

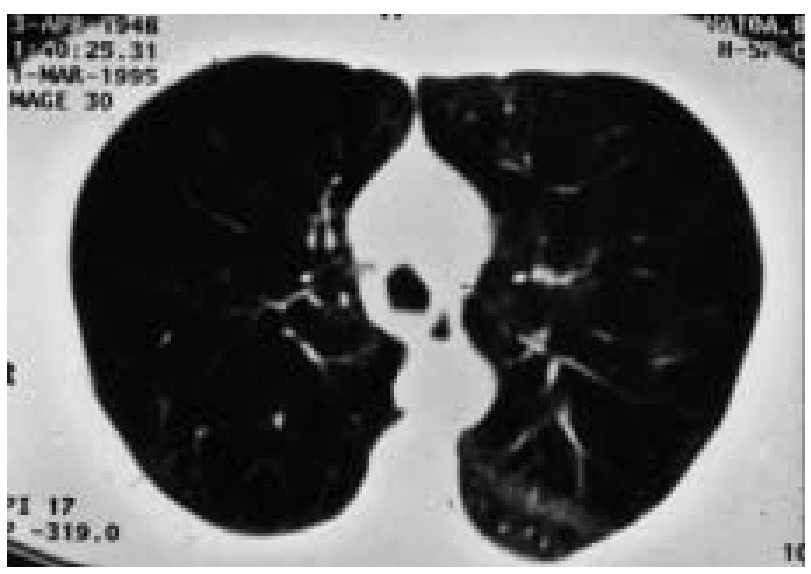

e)

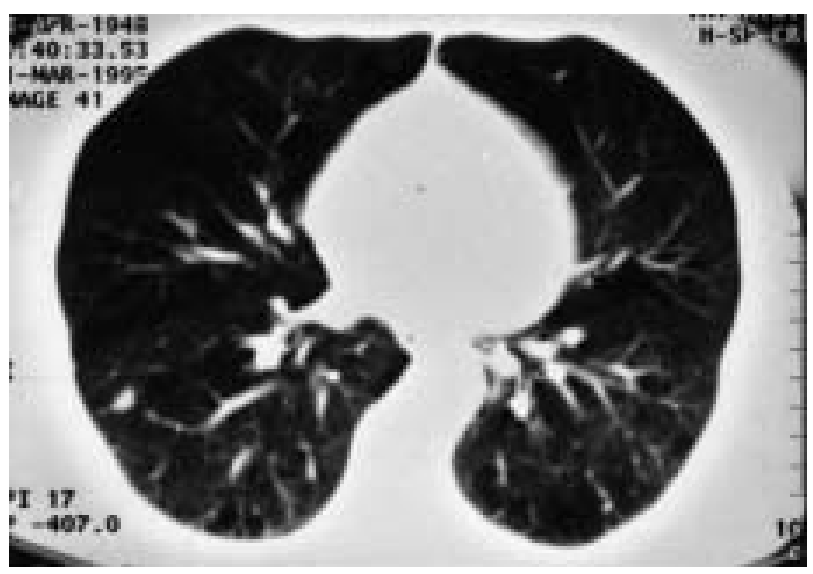

Fig. 2. - a) Preoperative posteroanterior radiograph shows predominant upper lobe emphysema with a distinct downward placement of the hilum. b) In the lateral projection the marked hyperinflation and the flattening and downward displacement of the diaphragm is clearly visible. c) Lung perfusion scan of the same patient confirms absent circulation in both upper lobes (right more than left). d and e) High resolution computed tomography shows severe emphysema in the upper lobes (d) and mild emphysema in the lower lobes (e) of the same patient. 


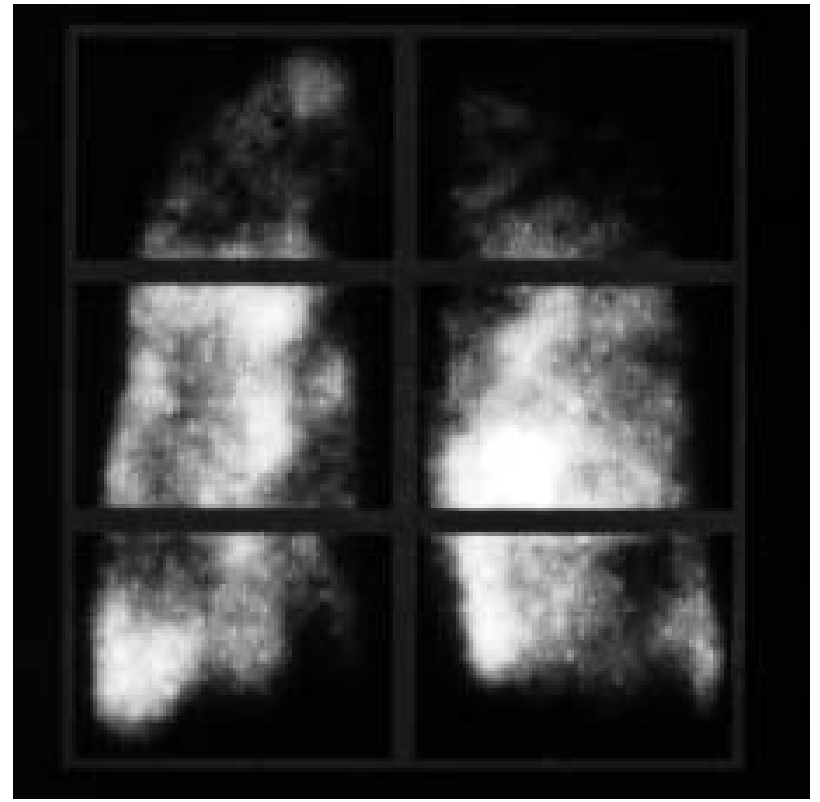

Fig. 3. - Lung perfusion scan showing a relatively homogeneous perfusion pattern with some scattered small spots of nonperfused "target areas".

Table 2. - Evaluation of patients for LVRS

Medical history and physical examination

Routine laboratory work

Pulmonary function test

Spirometry

Body plethysmography

$T \mathrm{~L}, \mathrm{CO}$

Arterial blood gas analysis

6 or 12 minute walking distance

PA and lateral chest radiograph (also in exhalation)

High resolution CT of the chest

Radionuclide-perfusion scan

PA: posteroanterior. For further definitions see table 1.

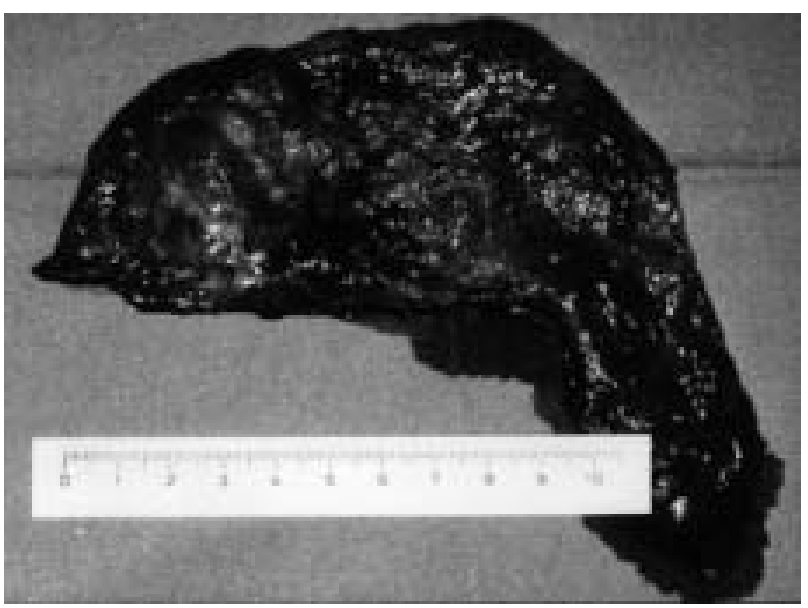

Fig. 4. - "Hockey-stick" shaped resection specimen of a right upper lobe. the tissue is deflated and does not reflect the actual volume.

It may be applied either unilaterally or bilaterally. The lung tissue can be stapled and resected with or without buttressing of the staple lines with xenopericardium. As an alternative, thermic energy may be applied by laser on the surface of the lung in order to "shrink" its volume.

\section{Median sternotomy}

COOPER et al. [17] started to perform LVRS bilaterally by median sternotomy in January 1993, and pursue this operation with excellent results [22]. Median sternotomy provides a good exposure of both lungs, especially the anterior and apical parts and allows palpation of the lung tissue. In addition, this approach does not interfere with chest wall muscles and does not cause painful intercostal nerve damage if the chest tubes are placed below the rib cage. The disadvantage of sternotomy is the impaired access to the lower lung lobes, especially on the left side.

After division of the sternum, the pleura is incised sequentially in order to keep the lung in place at the nonoperation site. Adhesions, which can be quite extensive in some patients, have to be dissected. The most damaged lung regions remain overdistended for much longer at the nonventilated lung, whereas the less emphysematous lung parts become atelectatic. These regions correspond with the target areas for resection, previously identified by chest CT and lung perfusion scans.

With the aid of mechanical stapling devices about $20-30 \%$ of the lung volume is resected. This is generally a nonanatomical wedge resection and the amount and sites of resection are imprecisely defined. In cases with predominantly destroyed upper lobes the resection usually starts medially on the horizontal fissure of the middle lobe or on the base of the lingula, proceeding further apically and dorsolaterally resulting in a "U-shaped" or "hockey stick" shaped piece of resection (fig. 4). In other cases the apical segments or the basal segments of the lower lobes are resected. COOPER [25] proposed to buttress the staple lines with strips of bovine pericardium in order to prevent extensive air leaks through the staple holes of the fragile lung tissue [26]. In the few cases of complete lobar destruction, an anatomical lobectomy can be performed [22].

The lung is reventilated and carefully checked for air leaks and whether the remaining lung volume fills out the thoracic cavity. If airspace persists in the apical regions COOPER and co-workers [17, 22] suggest dissection of the parietal pleura of the apex to produce a so-called "pleural tent". The parietal and visceral pleura are then in apposition and seal possible air leaks.

Two drainage tubes are placed on each side and the parietal pleura is closed with sutures. Ventilation is restored and the opposite side is resected.

\section{Thoracotomy}

Thoracotomy is favoured by groups who prefer "an open" procedure and are dealing with a case of predominant unilateral emphysema [22, 27]. In addition, some surgeons convert VAT to thoracotomy if extensive adhesions are present, which may result in air leaks from the dissection. They expect to control and seal air leaks more easily through an open approach. There are unpublished reports from groups who even perform LVRS through bilateral thoracotomy. Usually muscle sparing incisions are utilized in the 4th intercostal space (ICS) for an upper lobe type or an incision in the 5th 
or 6th ICS for predominant lower lobe emphysema. Resection technique and selection of target areas are comparable to the approach through median sternotomy. The major advantage of thoracotomy is a better access to the lower lobes. However, since even musclesparing incisions interfere with thoracic wall muscles, thoracotomy is not considered ideal for these critical patients and should be avoided as a simultaneous bilateral approach.

\section{Video-assisted thoracoscopy}

We are performing bilateral LVRS by VAT since it provides a good approach to all parts of the lungs through small incisions, which might result in minor morbidity.

Patients with predominantly upper lobe and/or middle lobe emphysema are placed supine and the less afflicted side is operated upon first. If the resection is planned in the lower lobes and/or posteriorly, the patient is placed laterally and the position changed after completion of the first side. Three $11.5 \mathrm{~mm}$ trocars are placed in the 7 th or 8 th ICS and a $5.5 \mathrm{~mm}$ in the 4th ICS. A $10 \mathrm{~mm}$ rigid, $25^{\circ}$ angled thoracoscope is used. The resection is aimed at the most destroyed tissues, identified previously by CT scans and perfusion scintigraphy. In some cases target areas can be visualized by observation of delayed resorption atelectasis. However, we consider visual inspection or palpation of the lung for targeting resection areas of minor importance, and rely more on imaging methods (HRCT, perfusion scintigraphy or single positron emission computed tomography (SPECT)).

The "target areas" are presented by an endoscopic lung forceps and resected by successive application of endoscopic staplers. For predominantly upper lobe disease the resection starts at the base of the lingula or the middle lobe, heading further apically and then dorsolaterally, resulting in "hockey stick" or "U" shaped excised pieces of lung with a cumulative volume of approximately $20-30 \%$ on each side. In predominantly lower lobe disease (typically alpha-1-AT deficiency) the basilar segments of the lower lobes, the lingula or middle lobe or both are resected. In the diffuse type of emphysema multiple wedge resections of the most destroyed areas are performed. The resected specimens are deflated and removed through the largest trocar site. The amount and sites of resections are intended to be identical to an open approach.

In contrast to others $[22,27,28]$, we do not buttress the staple lines with xenopericardium since we have observed no or minor air leaks in our initial patients at the end of the procedure. This experience is now confirmed in a larger series of patients and documented by our drainage time [29], which is equal or shorter compared to other groups [17, 22, 27, 30]. Furthermore, we do not perform pleural tents nor pleural abrasion or talc poudrage routinely. Two drainage tubes on each side are placed through the anterior trocars and suction of $-10 \mathrm{~cm} \mathrm{H}_{2} \mathrm{O}$ is applied.

Several centres have reported their results with a unilateral thoracoscopic resection [28, 30, 31]. They achieved significant functional improvement, although of lesser magnitude than with the bilateral procedure. However, unilateral resection may be indicated in the rare case with predominantly unilateral disease or in patients with contraindications to bilateral operation (i.e. pleurodesis, previous thoracotomy). All other patients should preferentially undergo bilateral resection.

WAKABAYSHI [32] recently described the results of applying thermic energy onto the surface of emphysematous lungs by VAT using a sapphire contact neodymiumyttrium aluminium garnet laser (Nd-YAG). The goal of this procedure, called "thoracoscopic laser pneumoplasty", is to achieve a shrinking of the underlying lung parts. In a retrospective analysis of 500 consecutive procedures in 443 patients, subjective and objective functional improvements were reported in the majority [32]. Since data of an objective functional follow-up were available in only 229 patients the results might be biased. McKenna et al. [28] conducted a prospective randomized trial comparing stapled lung resection with laser pneumoplasty and reported less favourable functional results and a longer drainage time in the laser group. These finding have been corroborated by others [30]. We therefore do not believe that laser pneumoplasty should be used as the sole method for volume reduction.

\section{Anesthesia and postoperative management}

For all surgical approaches a combination of continuous thoracic epidural analgesia with total intravenous anaesthesia is used [19]. A left-sided double-lumen endotracheal tube is placed for one-lung ventilation to enable resection on the collapsed lung and ventilation of the contralateral lung with an inspired oxygen fraction of 1.0 .

Extubation is performed in the theatre immediately following the operation. Local anaesthetics are given continuously via an epidural catheter for control of postoperative pain, allowing early physiotherapy and mobilisation. Adequate pain control remains an important factor in the early postoperative phase and includes oral analgetics as well as patient-controlled analgesia with opiates.

Perioperative antibiotics, consisting of amoxycillin, or according to microbiological findings, are given perioperatively for 3-5 days.

The chest tubes are connected to a chest tube drainage system with suction of $-10 \mathrm{cmH}_{2} \mathrm{O}$, usually increased up to $-20 \mathrm{cmH}_{2} \mathrm{O}$ after $3-5$ days. Other groups recommend water sealing [22] or connecting the tubes to Heimlich valves [33].

\section{Morbidity and mortality}

All patients in our prospective series [29] were extubated immediately at the end of surgery and only one patient had to be reintubated and ventilated for half a day. Six patients developed pneumonia (fever, pulmonary infiltrate on chest radiograph, elevated C-reactive protein) and were successfully treated with antibiotics. In our experience with additional patients $(n=36)$ postoperative pneumonia was observed less frequently, which is more in accordance to the incidence of this complication (4-20\%) by other groups [22, 27, 31]. This complication seems to be less frequent after a unilateral procedure [31]. 
The median chest tube drainage time was 6.5 (range 3-19) days and in seven patients the drainage time was prolonged (i.e. $>7$ days) [29]. The mean hospitalization time was 15 (range 7-26) days. No relevant differences in chest tube drainage time between different surgical approaches have been reported [17, 29], but differences between groups have been noted [17, 27, 29, 30]. Furthermore, it seems that buttressing of the staple lines does not clearly lower the drainage duration, at least in comparison to our own experience with VAT resection using an endoscopic stapler. None of our patients was discharged with a chest tube.

Perioperative mortality ( $<30$ days) was zero in our prospective study population [29] and did not increase with more patients (36 patients, April 96). Other centres with comparable selection criteria also report relatively low mortality rates of $2-4 \%[22,27,31]$.

\section{Functional results}

The Washington University Emphysema Surgery Group published their results with the first 20 cases in 1995 [17]. Further experience with a total of 84 patients was reported recently [34]. The average age of their patients was $60 \pm 9$ yrs. All suffered from a remarkable degree of bronchial obstruction with a mean FEV1 of $24 \%$ of predicted $\left(0.69 \pm 0.27 \mathrm{~L} \cdot \mathrm{s}^{-1}\right)$. The follow-up was 3 months for 53 patients, 6 months for 37 patients, and $1 \mathrm{yr}$ for
19 patients. The average increases in FEV1 were $58 \%$ (to $1.09 \mathrm{~L}), 64 \%$, and $87 \%$ (1.29 L) at 3, 6, and 12 months, respectively, and hyperinflation, measured by body plethysmography and assessed as total lung capacity decreased from a mean of $8.34 \mathrm{~L}$ ( $142 \%$ of predicted) to $6.76 \mathrm{~L}$ at three and to $6.93 \mathrm{~L}$ at six months, respectively. Even arterial oxygen tension $\left(\mathrm{Pa}, \mathrm{O}_{2}\right)$ increased significantly after surgery, from a mean of 8.0 to $9.0 \mathrm{kPa}(60-68$ $\mathrm{mmHg}$ ) at three months. Considerable improvements were reported in dyspnoea indices and quality of life scores.

We started to perform bilateral LVRS by VAT in 1994 and recently reported the results of our prospective study in 20 patients [29]. Our patients were selected according to the previously discussed criteria (table 1). The most striking improvement after LVRS relates to an amelioration of shortness of breath. Dyspnoea decreased from a mean of $3.4( \pm 0.6)$ to $1.8( \pm 0.9)$ as assessed by the Medical Research Council (MRC) dyspnoea score, by which shortness of breath is rated from 0 to 4 according to an increase in symptom severity.

The mean percentage increase in FEV 1 was $42 \%$. In four patients the changes in FEV1 were less than 150 $\mathrm{mL}$, but none showed worsening of FEV1 or vital capacity compared to preoperatively. In eight patients the increase in FEV1 was more than $300 \mathrm{~mL}$, one patient improved by 740 and another by $830 \mathrm{~mL}$. Our results, confirmed in the meantime by a larger series, compare favourably with those of other groups (table 3). The

Table 3. - Functional results after lung volume reduction surgery

\begin{tabular}{|c|c|c|c|c|}
\hline Author & $\begin{array}{l}\text { Pts } \\
\text { No. }\end{array}$ & Approach & Procedure & $\begin{array}{l}\Delta \mathrm{FEV} 1 \\
\%\end{array}$ \\
\hline $\begin{array}{l}\text { COOPER et al. } \\
\text { [17] } 1995\end{array}$ & 20 & MS & Bilateral stapled resection & 82 \\
\hline $\begin{array}{l}\text { DEMERTIZIS and co-workers } \\
\text { [35] } 1996\end{array}$ & 20 & MS & Bilateral stapled resection & 32 \\
\hline $\begin{array}{l}\text { EUGENE } \text { et al. } \\
\text { [36] } 1995\end{array}$ & 28 & VATSu & $\begin{array}{l}\text { KTP laser and/or Nd-YAG } \\
\text { laser, discretely bullous areas } \\
\text { and hyperinflated areas were } \\
\text { stapled }\end{array}$ & 34 \\
\hline $\begin{array}{l}\text { KEENAN et al. } \\
\text { [30] } 1996\end{array}$ & 67 & VATSu & $\begin{array}{l}\text { Nd-YAG laser }(10) \text {, stapled } \\
\text { resection }(23) \text {, stapled resection } \\
\text { with modest laser ablation (34) }\end{array}$ & 27 \\
\hline $\begin{array}{l}\text { LitTLE } \text { et al. } \\
\text { [37] } 1995\end{array}$ & 81 & VATSu & Nd-YAG & 15 \\
\hline $\begin{array}{l}\text { MCKeNNA et al. } \\
\text { [28] } 1996\end{array}$ & 72 & VATSu & $\begin{array}{l}\text { Nd-YAG (33) or stapled } \\
\text { resection (39) }\end{array}$ & $\begin{array}{l}33 \text { stapler group, } \\
13 \text { laser group }\end{array}$ \\
\hline $\begin{array}{l}\text { MILLER and co-workers } \\
\text { [27] } 1996\end{array}$ & 53 & $46 \mathrm{MS}, 7 \mathrm{Tu}$ & Stapled resection & 93 \\
\hline $\begin{array}{l}\text { NAUNHEIM and co-workers } \\
\text { [31] } 1996\end{array}$ & 50 & $\begin{array}{l}\text { VATSu, } \\
5 \text { patients } \\
\text { operated on } \\
\text { contralateral } \\
\text { side }\end{array}$ & Staled resection & 35 \\
\hline $\begin{array}{l}\text { WAKABAYASHI } \\
\text { [32] } 1995\end{array}$ & 483 & $\begin{array}{l}\text { VATSu, in } 57 \\
\text { cases subsequently } \\
\text { operation of the } \\
\text { opposite side }\end{array}$ & $\begin{array}{l}\text { Nd-YAG laser, type } 4 \text { bullae } \\
\text { were excised and sutured or } \\
\text { stapled }\end{array}$ & $\begin{array}{l}62 \text { in group with pre- } \\
\text { operative FEV } 1<14 \% \text { pred } \\
(\mathrm{n}=33) \\
28 \text { in group with pre- } \\
\text { operative FEV } 1 \geq 15 \% \text { pred } \\
(\mathrm{n}=191)\end{array}$ \\
\hline $\begin{array}{l}\text { YUSEN and co-workers } \\
\text { [34] } 1996\end{array}$ & 84 & MS & Bilateral stapled resection & 58 \\
\hline
\end{tabular}

$\triangle \mathrm{FEV}_{1}$ : change in forced expiratory volume in one second (FEV1) from pre- to postoperation; MS: median sternotomy; VATSu: unilateral video-assisted thoracoscopic surgery; Tu: unilateral thoracotomy; KTP laser: potassium titanyl-phosphate laser; NdYAG laser: neodymium-yttrium aluminium garnet laser; \% pred: percentage of predicted value. 
mean difference in total lung capacity from baseline was $1.0 \mathrm{~L}$ and the mean RV to TLC ratio decreased at three months after surgery from $0.64( \pm 0.09)$ to $0.55( \pm 0.07)$ $(\mathrm{p}<0.001)$. The results of pulmonary function tests immediately before discharge were similar to the functional data at three months [29].

The improvements in exercise capacity after bilateral LVRS, assessed by the timed walking distance, range between 38\% [29] and 60\% [27, 34]. These results indicate that after LVRS patients do not make full use of their improved lung function, a finding which is even more pronounced in transplant recipients [38]. In our experience, small increments of spirometric improvements are sufficient in many patients to allow them regular daily activity. Therefore, these generally older patients are no longer sufficiently motivated to perform systematic exercise training.

The concept of LVRS consists of removing lung parts almost completely destroyed by severe emphysema, i.e. tissue no longer involved in gas exchange. Consequently, we found no changes in $T \mathrm{~L}, \mathrm{CO}$, a parameter believed to reflect the amount of pulmonary gas exchange surface [29]. Ventilation-perfusion mismatch is another cause of hypoxaemia in patients with COPD and emphysema. Several groups observed a mild rise in the mean $\mathrm{Pa}, \mathrm{O}_{2}$ of their patients [27, 31, 34, 38]. They even reported that a considerable number of patients on oxygen at rest preoperatively no longer needed oxygen supplementation after LVRS. In contrast, in only one of our three patients, who satisfied the strict criteria for long term oxygen therapy (LOT) before LVRS $[6,7]$, the $\mathrm{Pa}_{\mathrm{a}} \mathrm{O}_{2}$ improved to such an extent, that he no longer required oxygen. Since no details about the criteria to prescribe LOT were made in the other studies [27, 31, 34, 38], we are not able to comment on these differing results.

Several groups have published their results with unilateral thoracoscopic volume reduction [28, 30, 31]. They consistently report a striking improvement in shortness of breath, although the achieved functional changes were less impressive in regard to an amelioration in FEV1 and a reduction in hyperinflation than with bilateral resection. The results which are observed after unilateral LVRS by stapling [28, 30, 31] are superior to those achieved with the laser technique [28, 30, 32, 36, 37].

Bilateral LVRS is the method of choice, whenever possible, since the functional results with unilateral LVRS are usually inferior (table 3). However, it is becoming clear that the improvements which are achieved by median sternotomy or by VAT are similar. This indicates the relatively minor influence of these two approaches on the functional outcome as long as the resections are performed appropriately.

\section{Lung volume reduction instead or before lung transplantation}

During the past decade lung transplantation has evolved into a successful treatment for patients with end-stage pulmonary emphysema [39]. However, a critical shortage of suitable donor lungs restricts transplantation to a small number of patients. Numerous patients with emphysema are ineligible because of their advanced age. Furthermore, many transplant recipients have a significant morbidity due to the inevitable immunosuppression and most experience a deterioration in their function over the years due to chronic rejection (i.e. bronchiolitis obliterans). Recently, the results in functional performance and survival after LVRS and after single or bilateral sequential lung transplantation were compared in a retrospective study [38]. Thirty-three patients underwent volume reduction (mean age 57 yrs), 39 patients single lung transplantation (55 yrs), and 25 patients bilateral lung transplantation (49 yrs). Early mortality (< 30 days) was 0 of 33,1 of 39 and 2 of 25 and mortality at 12 months was 1 of 33,4 of 39 and 4 of 25 in the LVRS, single, and bilateral lung transplantation group, respectively. At 6 months, mean FEV1 had improved by $79 \%$ (LVRS), $231 \%$ (single lung transplantation), and $489 \%$ (bilateral lung transplantation) over preoperative values. This analysis confirms that the functional improvements after LVRS are less impressive than those achieved by transplantation. Nevertheless, LVRS is an option for patients with debilitating symptoms, even when the FEV1 does not meet transplant criteria, or for patients who are not candidates for transplantation because of their advanced age. Furthermore, according to our personal experience with one patient and a report from the literature [40], LVRS seems not to hamper subsequent transplantation. Therefore, this type of surgery may be used as a means to delay transplantation in a subset of patients, and we offer it as a first option to all patients who fulfil the selection criteria.

\section{Open questions}

It may be deplored, that the results of LVRS have not been studied in a prospective randomized (multicentre) trial [41]. Only a randomized, controlled study in which half of the eligible patients undergo LVRS, and the other half receive optimal medical therapy during a number of years, would address the issues of long-term efficacy, cost-effectiveness and possible drawbacks from a rigorous scientific standpoint. However, several groups have convincingly shown that a majority of highly selected patients experience a significant and clinically relevant improvement, not only in symptoms, but also in pulmonary function, to an extent that cannot be achieved by optimized medical treatment.

Many questions in regard to the mechanisms responsible for the often striking improvement of dyspnoea after LVRS remain unanswered. It is conceivable, that a placebo effect plays an important role in this highly selected group of patients, who accept the risk of a surgical procedure. However, there is little doubt, that in the majority of patients the relief of shortness of breath is a consequence of changes in pulmonary mechanics, previously not achieved despite optimal medical therapy $[42,43]$. Nevertheless, the correlations between the amelioration of symptoms and the changes in conventional pulmonary function parameters, e.g. FEV1, residual volume, etc. are rather weak [44]. Recently, it was demonstrated, that the coefficient of retraction, an indicator of elastic recoil of the lung, improved after surgery 
[45]. We have evidence, that breathing pattern parameters at rest are altered by LVRS [46]. In addition, TESCHLER and co-workers [42] were able to demonstrate an increased force generation capacity of the inspiratory muscles, which was paralleled by a decrease in central respiratory drive.

Since by definition pulmonary emphysema is an irreversible process LVRS remains a palliative treatment for this disease. Up to now experience with the durability of the changes remain uncertain, but sustained improvements for at least $1 \mathrm{yr}$ have been reported [34]. Furthermore, only a complete follow-up of the operated patients will determine if progression of the underlying disease with accompanying functional deterioration will be at the rate usually anticipated. It might be slower because of changes in lifestyle and medical management, or accelerated because of the increased distending force on the residual emphysematous lung.

There is some evidence that patients with preferential upper lobe emphysema, or those with emphysema localized elsewhere, adjacent to less afflicted regions of the lung providing distinct target areas for resection, might benefit most from LVRS [23, 24]. Although the morphology of emphysema can be precisely assessed by high resolution $\mathrm{CT}$, no commonly accepted system for its grading and classification is in use at the moment. It is therefore not possible to correlate the reported functional improvements appropriately since the type of emphysema is not classified by the different centres. However, we and others [27] have observed that even some patients with a homogeneous type of emphysema without distinct target areas may experience a functional benefit from LVRS.

\section{References}

1. Siafakas NM, Vermeire P, Pride NB, et al. Optimal assessment and management of chronic obstructive pulmonary disease (COPD). Eur Respir J 1995; 8: 1398 1420.

2. American Thoracic Society Standards for the diagnosis and care of patients with chronic obstructive pulmonary disease (COPD) and asthma. Am Rev Respir Dis 1987; 136: 225-244.

3. Snider GL, Kleinerman J, Thurlbeck WM, Bengali ZH. The definition of emphysema: report of a national heart and blood institute, division of lung diseases, workshop. Am Rev Respir Dis 1985; 132: 182-185.

4. Tschernko E, Hofer S, Wisser W, Wanke T, Klepetko W, Haider W. Changes in ventilatory mechanics after bilateral lung volume reduction (Abstract). Anesth Analg 1996; 82: SCA12.

5. Anthonisen NR, Connett JE, Kiley JP, et al. Effects of smoking intervention and the use of an inhaled anticholinergic bronchodilator on the rate of decline of FEV1. The lung health study. JAMA 1994; 272: 1497-1505.

6. Nocturnal Oxygen Therapy Trial Group. Continuous or nocturnal oxygen therapy in hypoxemic chronic obstructive lung disease. Ann Intern Med 1980; 93: 391-398.

7. Report of the Medical Research Council Working Party. Long-term domiciliary oxygen therapy in chronic hypoxic cor pulmonale complicating chronic bronchitis and emphysema. Lancet 1981; 1: 681-685.

8. Casaburi R. Exercise training in chronic obstructive lung disease. In: Casaburi R, Petts TL, eds. Principles and practice of pulmonary rehabilitation. Philadelphia, W.B. Saunders, 1993; 204-224.

9. Casaburi R, Patessio A, Ioli F, Zanaboni S, Donner CF, Wasserman K. Reduction in exercise lactic acidosis and ventilation as a result of exercise training in patients with obstructive lung disease. Am Rev Respir Dis 1991; 143: 9-18.

10. Deslauriers J. History of surgery for emphysema. Semin Thorac Cardiovasc Surg 1996; 8: 43-51.

11. Reich L. Der Einfluß des Pneumoperitoneums auf das Lungenemphysem. Wien Arch $f$ Innere Med 1924; 8: 245-260.

12. Gaensler EA, Carter MG. Ventilation measurements in pulmonary emphysema treated with pneumoperitoneum. J Lab Clin Med 1950; 35: 945-959.

13. Carter MG, Gaensler EA, Kyllonen A. Pneumoperitoneum in the treatment of pulmonary emphysema. $N$ Engl $J$ Med 1950; 243: 549-558.

14. Brantigan OC, Mueller EA, Kress MB. A surgical approach to pulmonary emphysema. Am Surg 1957; 23: 789-804.

15. Brantigan OC. Pulmonary emphysema (Editorial). Surg Gynec Obstet 1961; 1: 117-119.

16. Brantigan OC, Kress MB, Mueller EA. The surgical approach to pulmonary emphysema. Dis Chest 1961; 39: 485-501.

17. Cooper JD, Trulock EP, Triantafillou AN, et al. Bilateral pneumectomy (volume reduction) for chronic obstructive pulmonary disease. J Thorac Cardiovasc Surg 1995; 109: 106-119.

18. Cooper JD, Nelems JM, Pearson FG. Extended indication for median sternotomy requiring pulmonary resection. Ann Thorac Surg 1978; 26: 413.

19. Triantafillou AN. Anaesthesia management for bilateral volume reduction surgery. Semin Thorac Cardiovasc Surg 1996; 8: 94-98.

20. Gaensler EA, Cugell DW, Knudson RJ, FitzGerald MX. Surgical management of emphysema. Clin Chest Med 1983; 4: 443-463.

21. Snider GL. Reduction pneumoplasty for giant bullous emphysema: implications for surgical treatment of nonbullous emphysema. Chest 1996; 109: 540-548.

22. Cooper JD, Patterson GA. Lung volume reduction surgery for severe emphysema. Semin Thorac Cardiovasc Surg 1996; 8: 52-60.

23. Slone RM, Gierada DS. Radiology of pulmonary emphysema and lung volume reduction surgery. Semin Thorac Cardiovasc Surg 1996; 8: 61-82.

24. Yusen RD, Lefrak S, The Washington University Emphysema Surgery Group. Evaluation of patients with emphysema for lung volume reduction surgery. Semin Thorac Cardiovasc Surg 1996; 8: 83-93.

25. Cooper JD. Technique to reduce air leaks after resection of emphysematous lung. Ann Thorac Surg 1994; 57: 1038-1039.

26. Juettner FM, Kohek P, Pinter H, Klepp G, Friehs G. Reinforced staple line in severely emphysematous lungs. J Thorac Cardiovasc Surg 1989; 97: 362-363.

27. Miller JI Jr, Lee RB, Mansour KA. Lung volume reduction surgery: lessons learned. Ann Thorac Surg 1996; 61: $1464-1469$.

28. McKenna RJ Jr, Brenner M, Gelb AF, et al. A randomized, prospective trial of stapled lung reduction versus laser bullectomy for diffuse emphysema. $J$ Thorac Cardiovasc Surg 1996; 111: 317-322.

29. Bingisser R, Zollinger A, Hauser M, Bloch KE, Russi EW, Weder W. Bilateral volume reduction surgery for 
diffuse pulmonary emphysema by video-assisted thoracoscopy. J Thorac Cardiovasc Surg 1996; 112: 875-882.

30. Keenan RJ, Landreneau RJ, Sciurba FC, et al. Unilateral thoracoscopic surgical approach for diffuse emphysema. J Thorac Cardiovasc Surg 1996; 111: 308-316.

31. Naunheim KS, Keller CA, Krucylak PE, Singh A, Ruppel $\mathrm{G}$, Osterloh J. Unilateral video-assisted thoracic surgical lung reduction. Ann Thorac Surg 1996; 61: 1092-1098.

32. Wakabayashi A. Thoracoscopic laser pneumoplasty in the treatment of diffuse bullous emphysema. Ann Thorac Surg 1995; 60: 936-942.

33. McKenna RJ Jr, Fischel RJ, Brenner M, Gelb AF. Use of the heimlich valve to shorten hospital stay after lung reduction surgery for emphysema. Ann Thorac Surg 1996; 61: 1115-1117.

34. Yusen RD, Trulock EP, Pohl MS, Biggar DG, The Washington University Emphysema Surgery Group. Results of lung volume reduction surgery in patients with emphysema. Semin Thorac Cardiovasc Surg 1996; 8: 99-109.

35. Demertzis S, Schäfers HJ, Wagner TOF, Hausen B, Fabel H, Borst HG. Bilaterale Lungenvolumenreduktion bei schwerem Emphysem. DMW 1996; 121: 427-433.

36. Eugene J, Ott RA, Gogia HS, Dos Santos C, Zeit R, Kayaleh RA. Video-thoracic surgery for treatment of end-stage bullous emphysema and chronic obstructive pulmonary disease. Am Surg 1995; 61: 934-936.

37. Little AG, Swain JA, Nino JJ, Prabhu RD, Schlachter MD, Barcia TC. Reduction pneumoplasty for emphysema: early results. Ann Surg 1995; 222: 365-374.

38. Gaissert HA, Trulock EP, Cooper JD, Sundaresan RS, Patterson GA. Comparison of early functional results after volume reduction or lung transplantation for chronic obstructive pulmonary disease. $J$ Thorac Cardiovasc Surg 1996; 111: 296-305.

39. Cooper JD, Patterson GA, Trulock EP, and the Washington University Lung Transplant Group. Results of single and bilateral lung transplantation in 131 consecutive recipients. J Thorac Cardiovasc Surg 1994; 107: 460-471.

40. Zenati M, Keenan RJ, Landreneau RJ, Paradis IL, Ferson $\mathrm{PF}$, Griffith BP. Lung reduction as bridge to lung transplantation in pulmonary emphysema. Ann Thorac Surg 1995; 59: 1581-1583.

41. Cutaia M. Lung reduction surgery - where are we heading (editorial). Chest 1996; 109: 866-869.

42. Teschler H, Stamatis G, El-Raouf Farhat AA, Meyer FJ, Costabel U, Konietzko N. Effect of surgical lung volume reduction on respiratory muscle function in pulmonary emphysema. Eur Respir J 1996; 9: 1779-1784.

43. Thompson AB. Lung volume reduction surgery for emphysema: answers are beginning to accumulate (editorial). Eur Respir J 1996; 9: 1771-1772.

44. Teschler H, Stamatis G, Farhat A, et al. Funktionelle Ergebnisse der chirurgischen Lungenvolumenreduktion beim schweren Lungenemphysem. DMW 1996; 121: $1248-1254$

45. Sciurba FC, Rogers RM, Keenan RJ, et al. Improvement in pulmonary function and elastic recoil after lung-reduction surgery for diffuse emphysema. N Engl J Med 1996; 334: 1095-1099.

46. Bloch KE, Li Y, Bingisser R, et al. Breathing pattern in severe pulmonary emphysema before and after thoracoscopic lung volume reduction surgery (Abstract). Am J Respir Crit Care Med 1996; 153: A748. 